\title{
Globe
}

Revue internationale d'études québécoises

\section{Jacques Portes, L'impossible retour de la France. De « La Capricieuse » à de Gaulle, Montréal, VLB Éditeur, 2008}

\section{Gérard Fabre}

Volume 14, numéro 1, 2011

URI : https://id.erudit.org/iderudit/1006000ar

DOI : https://doi.org/10.7202/1006000ar

Aller au sommaire du numéro

\section{Éditeur(s)}

Globe, Revue internationale d'études québécoises

ISSN

1481-5869 (imprimé)

1923-8231 (numérique)

Découvrir la revue

Citer ce compte rendu

Fabre, G. (2011). Compte rendu de [Jacques Portes, L'impossible retour de la France. De « La Capricieuse » à de Gaulle, Montréal, VLB Éditeur, 2008]. Globe, 14(1), 236-238. https://doi.org/10.7202/1006000ar d'utilisation que vous pouvez consulter en ligne.

https://apropos.erudit.org/fr/usagers/politique-dutilisation/ 
par de grands mythes, comme ce pouvait être le cas chez Anne Hébert par exemple, mais par le récit de soi, par l'expérience la plus intime du monde, par l'affirmation audacieuse d'une voix à nulle autre pareille. La voix de Miron, c'est aussi la présence d'un corps qui ne se gêne pas pour exister, pour se mettre lui-même en scène, pour incarner le poème, pour le travailler physiquement en l'enracinant dans le désir et la vie même. On oublie ce qu'une telle attitude a pu avoir de hardi et de libérateur dans le Québec de l'époque. Parlant à Flávio Aguiar d'un extrait de "La marche à l'amour " qui avait paru dans un journal, Miron se vantera d'avoir été le premier auteur québécois à représenter «l'acte de chair» dans un poème. C'était en 1957.

Michel Biron

Université McGill

Chaire de recherche du Canada

en littérature québécoise et francophone

\section{Jacques Portes}

Limpossible retour de la France.

De "La Capricieuse» à de Gaulle, Montréal, VLB Éditeur, 2008.

Cet ouvrage traite sans complaisance de la nature des relations franco-québécoises de 1855 à 1967. En quatre chapitres serrés et six annexes (où sont reproduits des textes de La Galissonnière, Tocqueville, Belvèze, Rameau de Saint-Père, Gaillard de Champris et de Gaulle), Jacques Portes montre que les gouvernants français - avant de Gaulle - ne souhaitent pas modifier l'équilibre des forces en Amérique du Nord. Ils s'appliquent à ne pas indisposer les maîtres de l'Empire britannique, dont ils escomptent l'appui diplomatique et militaire. Quant aux Canadiens français, malgré certaines apparences trompeuses, ils n'envisagent jamais sérieusement un retour à la "mère patrie ». Le premier chapitre revient sur l'épisode de «La Capricieuse»; le deuxième, sur les conséquences des traités de Paris (1763) et de Versailles (1783); le troisième, sur le lien conservateur qui se noue entre les deux sociétés par l'entremise de quelques individualités; le quatrième traite de l'ambiguïté des retrouvailles franco-québécoises. Portes ne verse donc pas dans un sentimentalisme déconnecté des rudes réalités géopolitiques. Il insiste sur le caractère implacable d'un processus historique : côté 
français, l'abandon sans gloire d'une colonie, derrière lequel se profile le pénible renoncement à un leadership mondial; côté canadien-français, le magnétisme qu'exercent les plus puissants, qu'ils soient anglais dans un premier temps, voisins américains ensuite.

Il existe cependant une entorse à la règle du développement séparé des deux sociétés. Cette entorse ne tient pas seulement au large fonds culturel et linguistique commun car le "contexte" ne saurait être figé en une substance donnée une fois pour toutes. Elle réside aussi dans l'action déterminée de quelques petits groupes, de part et d'autre de l'Atlantique, dont l'auteur montre l'engagement catholique le plus souvent nettement conservateur. Le chapitre III s'attache ainsi aux cas du capitaine de vaisseau Belvèze (qui commandait "La Capricieuse») et de Raymond Auzias-Turenne, descendant d'une vieille famille du Dauphiné, devenu "capitaliste prospère» en Amérique du Nord. Edme Rameau de Saint-Père et Henry Gaillard de Champris sont d'autres figures exemplaires du courant de pensée qui considère le peuplement d'origine française en Amérique du Nord comme une référence emblématique du maintien des vertus colonisatrices de la France métropolitaine. D'où l'activisme de ce groupe sans lequel les contacts "physiques» entre les deux sociétés auraient pu rester sporadiques.

Bien qu'il ne s'agisse pas de l'entrée privilégiée par l'auteur, une question se pose: la nostalgie, loin de paralyser la capacité d'évaluer les marges de manœuvre des descendants français d'Amérique, n’a-t-elle pas constitué le moteur des analyses scientifiques d'un Rameau par exemple, à l'image des observations effectuées par Tocqueville lors de son court séjour au Bas-Canada en 1831 ? Il faudrait revenir ici sur les thèses de Fernand Dumont concernant la dimension cognitive de toute idéologie, et l'appliquer en l'occurrence à «l'idéologie de la survivance», dont Rameau fut l'un des principaux promoteurs. Autrement dit, l'idéologie conservatrice (et, disons-le, d'inspiration plutôt antirépublicaine) n'a-t-elle pas fait office de biais nécessaire à la prise en compte par des intellectuels français de la réalité canadienne-française, fûtelle - et pour cause - initialement sublimée? Indéniablement, ce courant conservateur était plus apte alors à faire preuve d'empathie envers une société à la fois sous le joug britannique et sévèrement encadrée par son Église. L'attention portée à ces filières et filiations conservatrices (avec en particulier la fibre leplaysienne pour le "réformisme par le haut») permet de mieux comprendre, sur un plan généalogique, le positionnement du général de Gaulle en faveur de «l'avènement du Québec au rang d'un État souverain», comme en témoignent maintes formules utilisées par le chef d'État français lors d'une conférence de presse tenue le 27 novembre 1967. 
Avec pertinence, Portes met au jour des différences notables entre les histoires nationales: ainsi «[1]a venue de La Capricieuse à Québec et ses suites n'appartiennent $[\ldots]$ pas au champ des relations internationales, mais à celui de l'histoire sociale des Québécois, ce sont eux seuls qui ont réagi, écrit, chanté à propos de cet événement» (p. 35). En France, cet épisode n’a jamais donné lieu à la moindre commémoration, et reste aujourd'hui encore dans l'ombre. Un autre mérite de cet ouvrage est de souligner le mariage de raison franco-britannique, décidé au plus niveau gouvernemental, qui annihilait toute velléité de «reconquête» : édifiantes, à cet égard, les tendances anglophiles de la diplomatie française depuis le Second Empire («Aucun des deux gouvernements ne cherche noise à l'autre», p. 12) jusqu'à la Ve République. Le poids historique de cette alliance est tel que de Gaulle aura beaucoup de mal à faire passer son message sur le "Québec libre» auprès de ses propres ministres et du Quai d'Orsay, lequel fut particulièrement rétif comme le rappelle un de ses hauts fonctionnaires, Bernard Dorin, dans $L e$ Lobby du Québec à Paris. Les précurseurs du général de Gaulle (Québec Amérique, 2002). L'establishment français s'est révélé en la matière des plus "conservateurs», tant par routine que par idéologie.

Gérard Fabre, Institut Marcel Mauss École des hautes études en sciences sociales/CNRS, Paris 